\title{
Evaluation of Loss Generated by Edge Burrs in Electrical Steels
}

\author{
Asheraf Eldieb and Fatih Anayi \\ Wolfson Centre for Magnetics, Cardiff School of Magnetics, Cardiff CF24 3AA, U.K.
}

In large motor cores, faults caused by edge burrs between the core laminations can result in short circuit currents, which may be large enough to cause burning or complete machine failure. This paper simulates the impact of edge burrs on large motor lamination $(300 \mathrm{~mm} \times 300 \mathrm{~mm})$ by applying artificial shorts to lamination edges. This twofold study has investigated the impact of short circuit and the impact of short circuit positions on total power loss. Multiple shorts have been applied at different positions. It has been found that the induced eddy currents are largely dependent on the fault position (edge burrs) and the number of shorted laminations even when only two laminations are involved. This paper was further extended to include power loss separation into three components, and the power loss separation has been applied to the case of higher power losses obtained under specific short circuit conditions at different magnetizing frequencies. The power loss separation has shown a significant increase in eddy current loss components with increasing number of shorted laminations.

Index Terms-Anomalous loss, conductance, contact points, eddy currents, edge burrs, hysteresis loss.

\section{INTRODUCTION}

$\mathbf{T}$ HE CORES of electrical machines are normally built from thin electrical steel laminations to reduce the eddy current loss for high efficiency operation [1]. Each lamination is coated on both sides with an inorganic coating. This thin layer of 1 to $3 \mu \mathrm{m}$ thick is used to prevent the direct electrical contact between the laminations. The process of punching and cutting the electrical steel causes mechanical stress, which deforms the sheet and deteriorates its magnetic properties [2]. In general, the cores of electrical machines are subjected to different processes, which may have a direct impact on their properties. These include, mechanical damage during assembly, rewind or re-wedge, foreign particle also during assembly, vibration, arcing, heating and degradation of the insulation between the sheets [3], [4]. During the cutting process, however, mechanical deformations shear causes burrs on the cut edges [5]. These burrs tend to cause insulation breakdown between the sheets resulting in electrical shorting between the stacked laminations. If this electrical shorting covers several laminations, high currents can circulate leading to a significant increase in power loss and local overheating, which may cause burning or melting of the laminations, and thus it causes the potential for complete machine failure [6], [7]. The approach in [7] has predicted the impact of edge burrs by computer simulation of the core model; each model representing different burr positions and sizes in the core. Recently, different approaches have been applied to study the impact of edge burrs on core laminations, e.g. [8] has studied the impact of connected edges on the losses of ring core sample. The study has shown a dramatic increase in the eddy current power loss when connecting core edges. Mazurek et al. [9] studied the effect of interlaminar faults on a $350 \mathrm{kVA}$ three-phase transformer; the short circuits being applied at three stages to short out 33, 50, and 66 laminations at set positions. The total

Manuscript received August 31, 2015; revised December 31, 2015; accepted February 2, 2016. Date of publication February 15, 2016; date of current version April 15, 2016. Corresponding author: F. Anayi (e-mail: anayi@cardiff.ac.uk).

Color versions of one or more of the figures in this paper are available online at http://ieeexplore.ieee.org.

Digital Object Identifier 10.1109/TMAG.2016.2527361

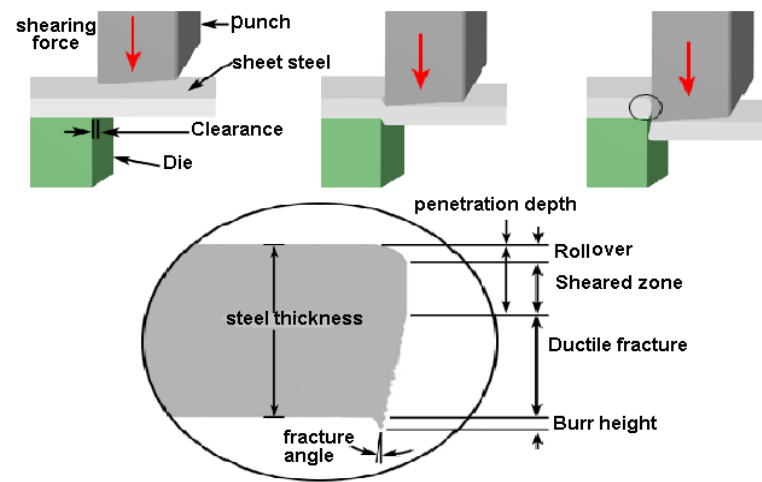

Fig. 1. Cutting process of a lamination and created edge burr. Reproduced from [13].

power loss of the core was measured using three-phase power analyzer and the localized power loss was measured by means of initial rate of rise of a temperature method. The obtained results have shown an increase of $13 \%$ at $1.5 \mathrm{~T}$ and by $100 \%$ at $1.8 \mathrm{~T}$, the case where 66 laminations were shorted together. Furthermore, large increase in temperature was noticed in the burred regions. Most of the published works on the effect of edge burrs were carried out on grain-oriented electrical steels. This paper focuses on the impact of short circuit and short circuit position on a non-oriented electrical steel.

Further interlaminar shorts are induced by small insulation faults on the lamination surface inside the center of the core middle. However, the probability of such faults to occurring is very low and stochastic [10]. Therefore, its impact is not considered in this paper.

Burr is formed during the punching process of the sheets, which results in interlayer short circuits as well as short circuit at the cut edges. Burr formation is caused by shearing during the separation of the metal by two blades of the guillotine. Moving blade contacts the sheet that starts to roll over, and this causes an increase of the load leading to fracture shear stress of the sheet [11]; at this stage of cutting process, the load increases causing a crack that leads to rapid breakthrough involving a ductile fracture and formation of burrs [12]. Fig. 1. shows the impact of the cutting process. 


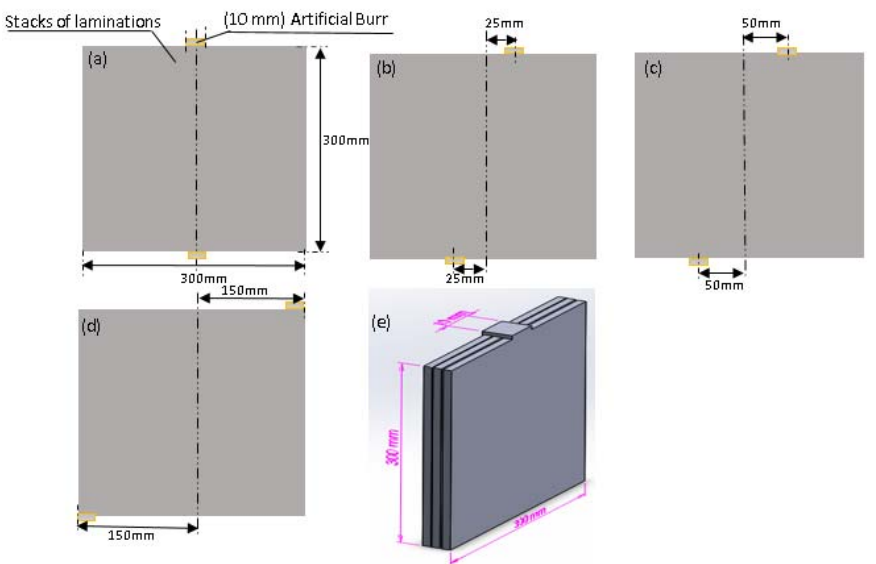

Fig. 2. (a)-(d) Stacks of two and three laminations with artificial burrs at different set-points. (e) Stacks of three laminations with artificial burrs at mid-point.

The aim of this paper is to present the impact of short circuit and its position on motor laminations edges.

\section{EXPERIMENTAL PROCEDURE}

In this experimental work, the packs of two and three $0.5 \mathrm{~mm}$ thick $3 \%$ Si non-oriented steel laminations were short circuited by lead free solder in the rolling direction, as shown in Fig. 2. A solder of $10 \mathrm{~mm}$ long, $0.5-1 \mathrm{~mm}$ thickness was introduced at four different set-points. In order to investigate the impact of artificial burrs, power loss measurement on the stacks has been conducted first, while no-fault was applied. Then, the power loss was measured for stacks, while the artificial burrs present at different set positions, as shown in Fig. 2.

The power loss measurement of the test specimens was carried out by means of a large scale strip tester $(300 \mathrm{~mm} \times 300 \mathrm{~mm})$. The system consists of a computer with virtual instrumentation software LabVIEW and a data acquisition/generation card NI BNC-2110(DAQ). It generates a sinusoidal voltage signal that is fed into the power amplifier, which provides the magnetizing current for the strip tester. The power loss generated in the test specimen is measured by the system from the magnetizing current and the induced secondary voltage in the strip tester. This method enables the system to measure the power loss in single laminations or packs of two or three laminations at a peak magnetic flux density of $1.5 \mathrm{~T}$ and magnetizing frequencies of $25,50,100$, 200, and $400 \mathrm{~Hz}$. Each measurement was repeated three times with an estimated uncertainty in the determination of power loss of $\pm 1 \%$. Importantly, an appropriate time delay was left between the measurements in order that the test specimens were allowed to be demagnetized fully and stabilized thermally. The results of the measurements have shown an increase in power loss when the edge burrs are present in the test specimens compared with burr-free specimens. The power loss was the highest when the artificial burrs were applied at the mid-point of the multilayer test specimen. As the axial displacement between the contact points was increased, the power loss gradually reduced. The results are shown in Figs. 3 and 5, which show how the power loss for

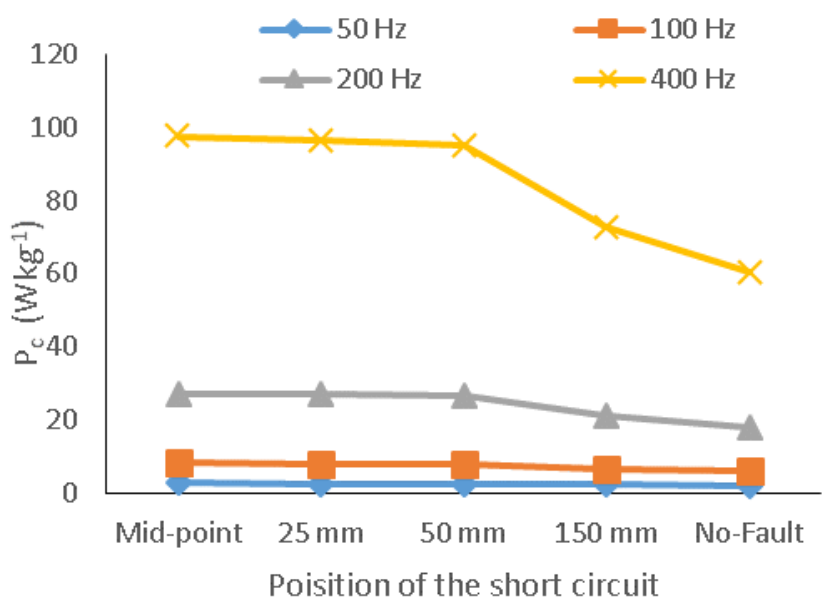

Fig. 3. Measured power loss for stacks of two laminations with different set-points of short circuits.

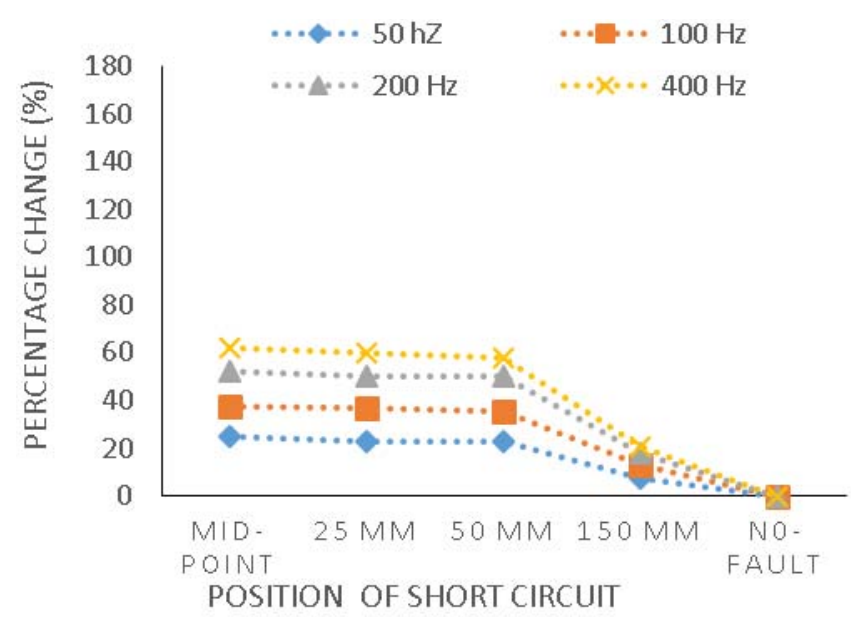

Fig. 4. Relative percentage change between no-fault and fault condition for three laminations shorted at four set-points.

test specimen packs of two and three non-oriented electrical steel laminations changes with and without the applied faults. Figs. 4 and 6 show the changes between the fault and no-fault conditions for test specimen packs of two and three, respectively.

\section{Core Loss Separation}

In 19th century, Steinmetz separated the power loss for the first time into two main components, hysteresis loss $P_{h}$ and eddy current loss $P_{e}$ [14]. However, this method gives large discrepancies compared with the experimental results, mainly at high frequencies and high flux densities, the difference between the measured and calculated losses is called excess or anomalous loss $P_{a}$, which was added by [15], and then the total power loss is the combination between the three components

$$
\begin{aligned}
P_{C} & =P_{h}+P_{e}+P_{a} \\
& =K_{h} f B_{\mathrm{pk}}^{n}+K_{e} f^{2} B_{\mathrm{pK}}^{2}+K_{a} f^{1.5} B_{\mathrm{pK}}^{1.5} .
\end{aligned}
$$

When divided by the frequency $f$, (1) will become

$$
P_{c} / f=K_{h} B_{\mathrm{pK}}^{n}+K_{e} f B_{\mathrm{pK}}^{2}+K_{a} \sqrt{ } f B_{\mathrm{pK}}^{1.5}
$$




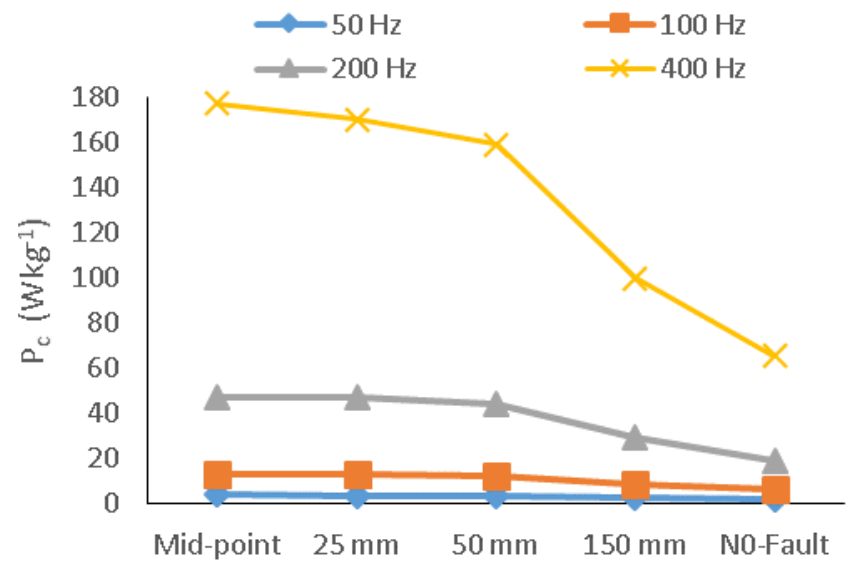

Poisition of the short circuit

Fig. 5. Measured power loss for stack of three laminations with different set-points of short circuits.

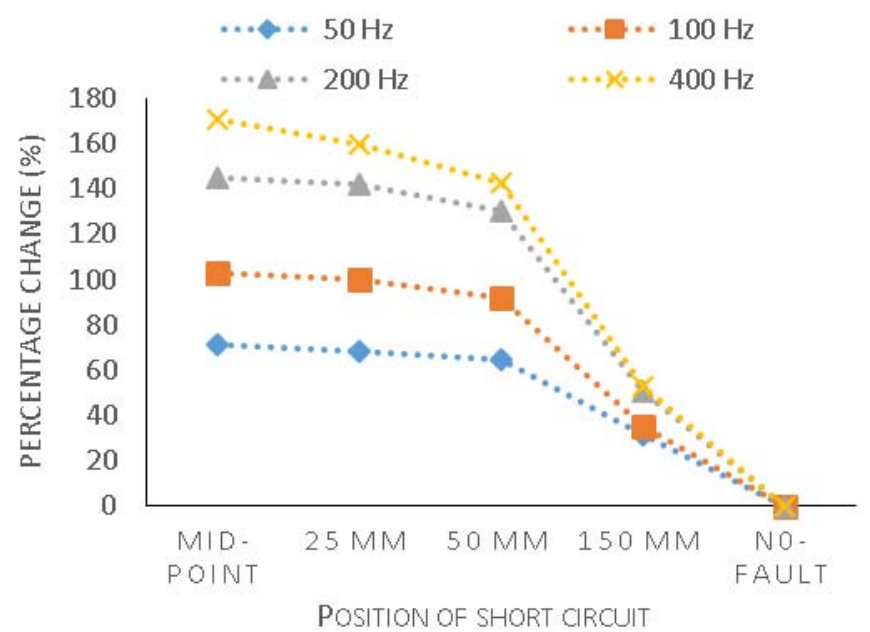

Fig. 6. Relative percentage change between no-fault and fault condition for three laminations at different short circuit positions.

where $f$ is the magnetizing frequency $(\mathrm{Hz})$ and $B_{\mathrm{pK}}$ is the peak flux density (T). $K_{h}, K_{e}$, and $K_{a}$ refer to hysteresis, eddy current, and anomalous loss coefficients, which can be extrapolated from experimental data, and it is assumed that $n$ is constant. The terms in (2) can be represented as constant coefficients

$$
P_{c} / f=D+E f+G \sqrt{ } f
$$

where

$$
D=K_{h} B_{\mathrm{pK}}^{n} ; \quad E=K_{e} B_{\mathrm{pK}}^{2} ; \quad G=K_{a} B_{\mathrm{pK}}^{1.5} .
$$

Here, $D, E$, and $G$ are the hysteresis loss per cycle, the eddy current power loss per cycle, and the excess loss per cycle, respectively. These coefficients are obtained by plotting $P_{c} / f$ versus $\sqrt{ }(f)$ for different values of flux density and frequency. Therefore, (3) can be modified and becomes

$$
P_{c} / f=D+E(\sqrt{ } f)^{2}+G \sqrt{ } f .
$$

Then, the coefficients of power loss components $D, E$, and $G$ are found by polynomial curve fitting. Based on the method stated above, the power loss components for

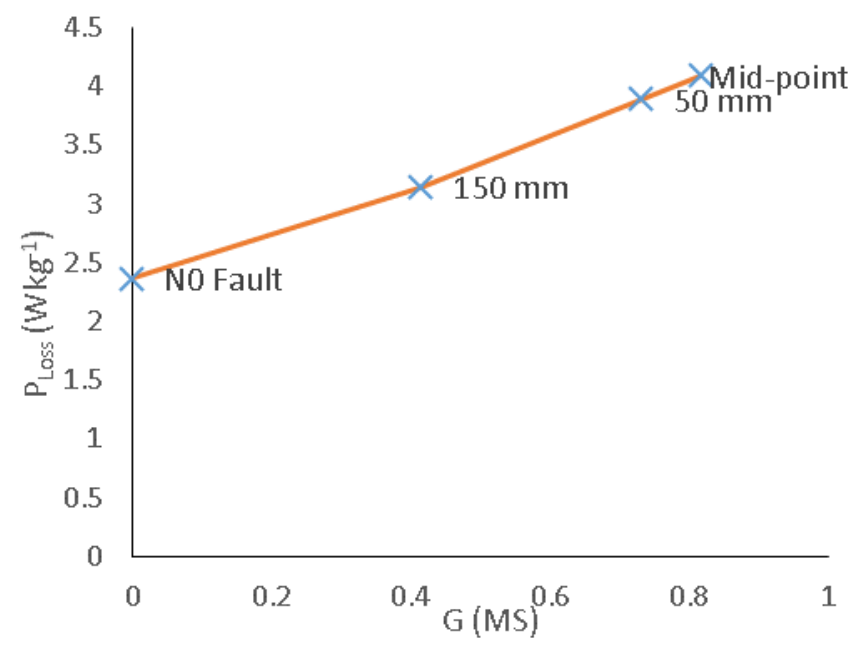

Fig. 7. Relationship between conductance and power loss at no-fault and three fault conditions for pack of three laminations.

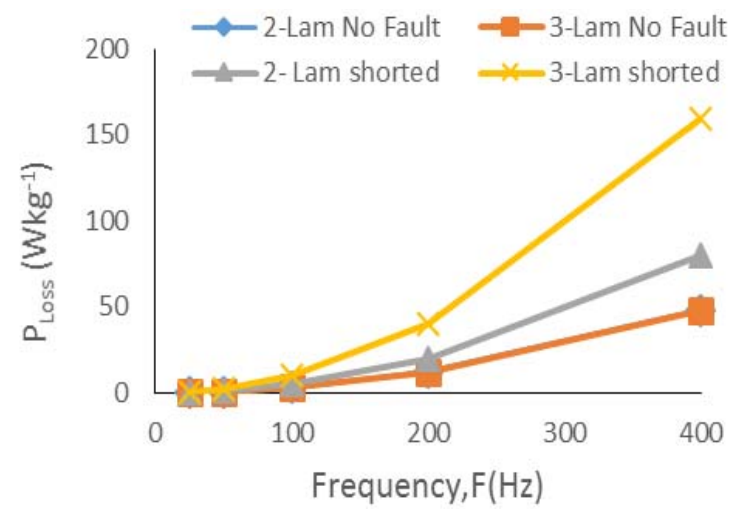

Fig. 8. Derived eddy current power loss for two and three laminations with fault in mid-point position.

the material under investigation implementing two and three pack of laminations, were firstly obtained in case of no fault is applied then while a short circuit is present at mid-point (zero separation). This type of short circuits provides lower electrical resistance between the contact points; therefore, higher eddy currents and, hence, higher power losses are produced.

\section{Discussion of Results}

The results of power loss measurement on the material under investigation have shown the impact of short circuiting the edges of the laminations. When a short circuit is present, an increase in power loss is observed, which is due to the increase on eddy currents. It has also been shown that the losses increase with increasing number of shorted laminations, which increasing the induced eddy current, as a result of a larger fault loop for the number of shorted laminations. This investigation has specifically studied the impact of burrs and their influence on core lamination performance. Single short circuits were applied to the specimen at different set-points. It has been observed that the impact of burr contacts differs from one case to another as compared with the no-fault case. Hence, a $71 \%$ increase in power loss was observed when the shorts were applied at the mid-point. A gradual decrease 


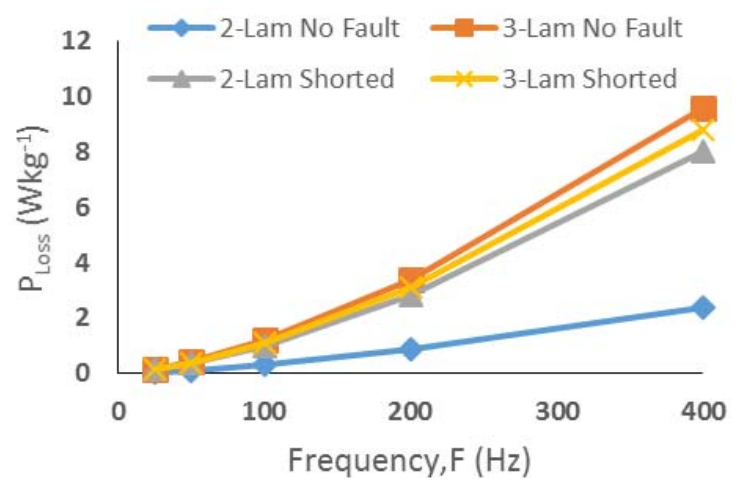

Fig. 9. Derived anomalous loss for two and three lamination with fault in the mid-point position.

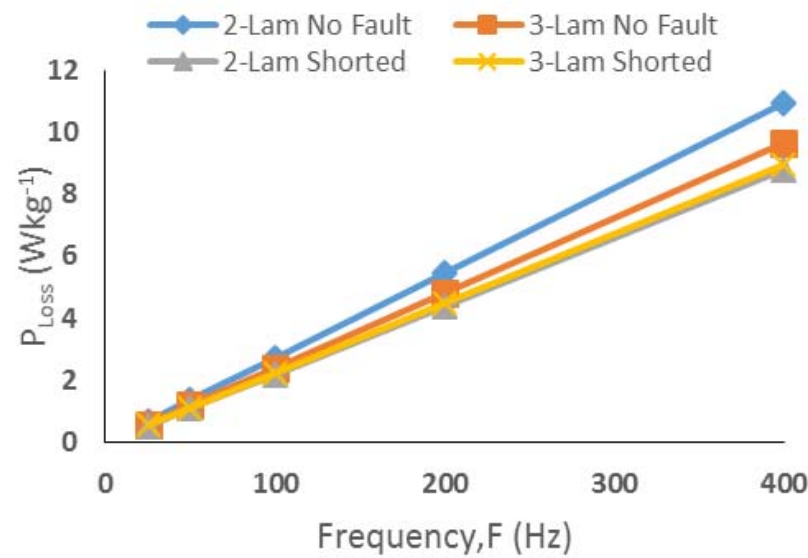

Fig. 10. Derived hysteresis loss for two and three laminations with fault in the mid-point position.

in power loss was observed by increasing the axial off set between the contact points, e.g., $68.28 \%$ at $25 \mathrm{~mm}$ axial off set, $64.48 \%$ at $50 \mathrm{~mm}$ axial off set, and $31.07 \%$ at $150 \mathrm{~mm}$ axial off set. In order to investigate the impact of the position of the short circuit, an Agilent 34420A Micro-Ohmmeter was used to measure the conductance between the contact points for each fault position. The results presented in Fig. 7 have shown larger conductance when a fault was applied at mid-point compared with the other three cases of axial off sets. Hence, the conductance was found to be decreased with increasing the axial off, and it was found to be the lowest when the fault was applied at $150 \mathrm{~mm}$ axial off set. There was a clear relationship between the measured conductance between the contact points and the variation of power loss based on burr position. Three sets of conductance measurements were taken and they show a good repeatability, the average was considered in this investigation. This paper has theoretically studied the power loss separation using the extrapolation method of power loss separation, and the purpose of this investigation was to determine which component has a significant role in increasing the power loss while edge burrs are present. Based on the results of this investigation, the eddy current power loss is found to be the dominant factor due to the impact of the short circuit, while the hysteresis and anomalous loss components are not showing any large impact, which may be expected for the material under investigation. The changes in the three power loss components with and without faulted conditions are shown in Figs. 8-10.

\section{CONClusion}

This paper has presented an experimental study of the effect of short circuit position on total power loss for stacks of two and three laminations of a non-oriented electrical steel. It was found that the power loss increases with increase in the number of shorted laminations and this increase of loss is dependent on position of the short circuit. This paper has provided a good indication of the severity of short circuits relative to their position in the motor core.

\section{REFERENCES}

[1] S. B. Lee, G. B. Kliman, M. R. Shah, W. T. Mall, N. K. Nair, and R. M. Lusted, "An advanced technique for detecting inter-laminar stator core faults in large electric machines," IEEE Trans. Ind. Appl., vol. 41, no. 5, pp. 1185-1193, Sep./Oct. 2005.

[2] A. Kedous-Lebouc, B. Cornut, J. C. Perrier, P. Manfé, and T. Chevalier, "Punching influence on magnetic properties of the stator teeth of an induction motor," J. Magn. Magn. Mater., vols. 254-255, pp. 124-126, Jan. 2003.

[3] R. M. Tallam et al., "A survey of methods for detection of stator-related faults in induction machines," IEEE Trans. Ind. Appl., vol. 43, no. 4, pp. 920-933, Jul./Aug. 2007.

[4] C. Rickson, "Electrical machine core imperfection detection," IEE Proc.-Elect. Power Appl., vol. 33, no. 3, pp. 190-195, May 1986.

[5] P. Handgruber, A. Stermecki, O. Biro, and G. Ofnery, "Evaluation of interlaminar eddy currents in induction machines," in Proc. 39th Annu. Conf. IEEE Ind. Electron. Soc. (IECON), Nov. 2013, pp. 2792-2797.

[6] P. Beckley, Electrical Steels for Rotating Machines, 1st ed. Stevenage, U.K.: The Institution of Engineering and Technology, 2002.

[7] M. B. Aimoniotis and A. J. Moses, "Evaluation of induced eddy currents in transformer sheets due to edge-burrs, employing computer aided design programs," in Proc. Athens Power Tech, vol. 2. Sep. 1993, pp. 847-850.

[8] E. Lamprecht and R. Graf, "Fundamental investigations of eddy current losses in laminated stator cores created through the impact of manufacturing processes," in Proc. 1st Int. Electr. Drives Prod. Conf. (EDPC), Sep. 2011, pp. 29-35.

[9] R. Mazurek, H. Hamzehbahmani, A. J. Moses, P. I. Anderson, F. J. Anayi, and T. Belgrand, "Effect of artificial burrs on local power loss in a three-phase transformer core," IEEE Trans. Magn., vol.48, no. 4, pp. 1653-1656, Apr. 2012

[10] M. C. Marion-Pera, A. Kedous-Lebouc, T. Waeckerle, and B. Cornut, "Characterization of SiFe sheet insulation," IEEE Trans. Magn., vol. 31, no. 4, pp. 2408-2415, Jul. 1995.

[11] S.-L. Ko and D. A. Dornfeld, "A study on burr formation mechanism," Trans. ASME J. Eng. Mater. Technol., vol. 113, no. 1, pp. 75-87, 1991.

[12] P. Baudouin, M. De Wulf, L. Kestens, and Y. Houbaert, "The effect of the guillotine clearance on the magnetic properties of electrical steels," J. Magn. Magn. Mater, vol. 256, pp. 32-40, Jan. 2003.

[13] Custompart.Net. (May 20, 2015). Sheet Metal Cutting (Shearing). [Online]. Available: http://www.custompartnet.com/wu/sheet-metalshearing.

[14] T. L. Mthombeni and P. Pillay, "Physical basis for the variation of lamination core loss coefficients as a function of frequency and flux density," in Proc. IECON, Paris, France, Nov. 2006, pp. 1381-1387.

[15] G. Bertotti, "General properties of power losses in soft ferromagnetic materials," IEEE Trans. Magn., vol. 24, no. 1, pp. 621-630, Jan. 1988. 